\title{
Assessment of Physical Stability and Antioxidant Activity of Polysiloxane Polyalkyl Polyether Copolymer-Based Creams
}

\author{
Atif Ali, Naveed Akhtar, and Haji Muhammad Shoaib Khan \\ Faculty of Pharmacy and Alternative Medicines, The Islamia University of Bahawalpur, Bahawalpur 63100, Pakistan \\ Correspondence should be addressed to Atif Ali; ajmaline2000@gmail.com
}

Received 5 March 2012; Revised 7 May 2012; Accepted 8 May 2012

Academic Editor: Ana B. Martin-Diana

Copyright (C) 2013 Atif Ali et al. This is an open access article distributed under the Creative Commons Attribution License, which permits unrestricted use, distribution, and reproduction in any medium, provided the original work is properly cited.

\begin{abstract}
The purpose of the present work was to investigate the changes on physical stability (color, creaming, liquefaction, $\mathrm{pH}$, conductivity, centrifugation, viscosity and rheological parameters) by non-ionic surfactant polysiloxane polyalkyl polyether copolymer based creams following inclusion of plant extract containing phenolic compounds. The antioxidant activity of the plant extract alone and after addition in the cream was assessed using the stable free radical 1,1-diphenyl-2-picrylhydrazyl (DPPH) assay. Physical stability was assessed by submitting the creams to storage at $8^{\circ} \mathrm{C}, 25^{\circ} \mathrm{C}, 40^{\circ} \mathrm{C}$, and at $40^{\circ} \mathrm{C}$ with $70 \% \mathrm{RH}$ (relative humidity) for a period of two months. Physical characteristics of polysiloxane polyalkyl polyether copolymer based creams, that is, color, creaming, liquefaction, centrifugation and $\mathrm{pH}$ were noted at various intervals for 2 months. The viscosities and rheological behavior of creams were determined using a rotational rheometer. Data were analyzed by using Brookfield Software Rheocalc version (2.6) with IPC Paste and Power Law (PL) math models. Cream with plant extract showed pseudo plastic behaviour with decreasing on viscosity. The Acacia nilotica (AN) extract alone and the cream containing this extract showed great antioxidant and free radical scavenging activities. Power Law and IPC analysis were found to fit all the rheograms.
\end{abstract}

\section{Introduction}

Plants produce a number of antioxidants against molecular damage from reactive oxygen species, and phenolic antioxidants are one of the major classes which act as photoprotectives [1]. In the recent years phenolics have gained considerable attention due to their use in skin care, such as dryness, eczema, acne, free radical scavenging, antiinflammatory, anti-aging, and skin protection effects [2]. Phenolics act as antioxidants in a number of ways [1] by formation of long-lived radical results, hydrogen donating phenolics and reactive oxygen species are able to modify the radical-mediated oxidation processes [2], by chelating metal ions with phenolics involved in the production of free radicals [3] and by inhibiting enzymes such as various cytochrome P450 isoforms, lipoxygenases, cyclooxygenase, and xanthine oxidase involved in radical formations [3].

Polysiloxane polyalkyl polyether copolymer (ABIL EM 90 ) is a nonionic surfactant [4] with outstanding heat and freeze/thaw stability. It is oil soluble, and its HLB value is
5. It is used as emulsifier for sun shield preparations with high content of organic and/or physical UV filters. It has high compatibility with active ingredients. It makes possible a dispersion of aqueous droplets within an oil phase [5].

Researchers have reported the antioxidant activity in vitro or in vivo of Acacia nilotica extract [6,7]. Acacia nilotica extract has antioxidant activity against hydroxyl, superoxide, and peroxyl radicals [8] and thus may play a role in the treatment of diseases involving free radicals and oxidative damage [9] such as cancer and aging. Incorporation of antioxidants and phenolic compounds topically has recently proved to symbolize a flourishing strategy for protecting the skin against oxidative damage [10], but there is no data in text in the best of our knowledge about their efficacy in topical preparations of Acacia nilotica extract and their influence on physical stability of the formulation.

Copious rheological studies have been conducted on emulsions [11]. Rheological properties can be divided into viscous, elastic, and plastic properties and combinations of these, viscoelasticity being the most important for semisolids. 
TABLE 1: Formulas of base and active cream.

\begin{tabular}{lccccc}
\hline Cream & Paraffin oil & Abil Em 90 & Plant extract & Fragrance & Deionized water \\
\hline Base & $14 \%$ & $2 \%$ & Nil & $1 \%$ & q.s $100 \%$ \\
Active cream & $14 \%$ & $2 \%$ & $3 \%$ & $1 \%$ & q.s $100 \%$ \\
\hline
\end{tabular}

Semisolids, like emulsions, combine solid behavior and liquid properties in the same material. The dominating properties and the values for rheological parameters depend on the stress and the duration of stress application. Analysis of viscoelastic materials is designed not to destroy the structure, so that measurements can provide information on the intermolecular and interparticle forces in the material [12].

The purpose of the present work was to investigate the changes on physical stability (color, creaming, liquefaction, $\mathrm{pH}$, conductivity, centrifugation, viscosity, and rheological parameters) by nonionic surfactant polysiloxane polyalkyl polyether copolymer-based creams following inclusion of plant extract containing phenolic compounds.

\section{Experimental}

2.1. Materials. Polysiloxane polyalkyl polyether copolymer (ABIL EM 90) was purchased from the Franken Chemicals Germany, paraffin oil was purchased from Merck, Germany, 1,1-diphenyl-2-picrylhydrazyl (DPPH) was purchased from the Sigma Chemical Co. (St. Louis, MO, USA), and ethanol was purchased from the BDH England. Acacia nilotica bark was collected and identified by the Cholistan Institute of Desert Studies, and specimen was deposited by the Herbarium, The Islamia University of Bahawalpur (Voucher no. ANBK-01-01-10-030).

\subsection{Methods}

2.2.1. Preparation of the Extract. The air-dried ground ( 80 mesh) plant material ( $40 \mathrm{~g}$ for each sample) was extracted with each of the solvent-aqueous ethanol (ethanol: water, $80: 20 \mathrm{v} / \mathrm{v})(1 \mathrm{~L})$-for 6 hours at room temperature in mechanical mixer (Euro-Star, IKA D 230, Germany). The extract was separated from the residues by filtering through Whatman no. 1 filter paper. The residues were extracted twice with the same fresh solvent and extracts combined. The combined extracts were concentrated and freed of solvent up to one-tenth under reduced pressure at $45^{\circ} \mathrm{C}$, using a rotary evaporator (Eyela Co. Ltd., Japan). The concentrated extract was stored in a refrigerator $\left(-4^{\circ} \mathrm{C}\right)$, until used for analyses.

2.2.2. Free Radical Scavenging Activities. The free radical scavenging activity of the $\mathrm{H}$-donor ability was assessed by using an ethanol solution of DPPH, a stable nitrogencentered free radical. The DPPH shows maximum absorbency at $517 \mathrm{~nm}$, which decreases in the presence of $\mathrm{H}$-donor molecules. The DPPH stable free radical was used for the determination of free radical scavenging activity of extract [13]. In 5 microliter of aqueous ethanolic plant extract DPPH added to make the volume up to $100 \mu \mathrm{L}$ in 96-well plates. The contents mixed and incubated at $37^{\circ} \mathrm{C}$ for 30 minutes and the optical density measured at $517 \mathrm{~nm}$. Ascorbic acid was used as a standard. Ascorbic acid had a strong antioxidant property, that is why it was used as standard to evaluate the antioxidant activity of substances [14]. Experiments were done in triplicates. Results were taken as mean and standard error of mean of three independent experiments:

$\%$ DPPH scavenging activity $=\left(\frac{100-\mathrm{OD} \text { of test sample }}{\mathrm{OD} \text { of controlled } \times 100}\right)$.

2.2.3. Test Formulation. A cream stabilized by an anionic hydrophilic colloid (paraffin oil) was developed, based on polysiloxane polyalkyl polyether copolymer (Abil EM 90). Deionized water was used for the preparation of formulations (Table 1). The active extract was incorporated during mixing.

2.2.4. Physical Stability Assessment. Physical stability was assessed by submitting the creams to storage at $8^{\circ} \mathrm{C}, 25^{\circ} \mathrm{C}$, $40^{\circ} \mathrm{C}$, and at $40^{\circ} \mathrm{C}$ with $70 \% \mathrm{RH}$ (relative humidity) for a period of two months. Physical characteristics of creams, that is, color, creaming, liquefaction, centrifugation, and $\mathrm{pH}$, were noted at various intervals for 2 months. Centrifugal tests were performed for base and active cream immediately after preparation. The centrifugal tests were repeated for emulsions after 24 hours, 7 days, 14 days, 21 days, 28 days, 42 days, and 54 days of preparation. The centrifugal tests were performed at $25^{\circ} \mathrm{C}$ and at $5000 \mathrm{rpm}$ for 10 minutes by placing few grams of sample in disposable stoppered centrifugal tubes. Samples were collected for the evaluation of rheological behavior and viscosity measurements at the initial time and after one and two months. The viscosities and rheological behavior of creams were determined using a rotational rheometer with a cone-plate configuration (Brookfield DV-III Ultra) with a CP41 spindle. A Brookfield software program, Rheocalc V2.6, was also used. Approximately $0.2 \mathrm{~g}$ samples and a constant temperature of $25^{\circ} \mathrm{C}$ were used for the tests. Tests were repeated three times, each containing 10 values of shear rate. Following the determination of the flow type, flow curves were fit to the available mathematical models. Increased shear stresses were applied on the samples, and the shear rates and changes in viscosities were noted. Electrical conductivity using conductivity meter (WTW COND-197i, Germany) centrifugation using centrifuge machine (Hettich EBA 20, Germany) were performed. The $\mathrm{pH}$ of creams were measured using pH meter (WTW pH-197i, Germany).

\section{Data Analysis}

Data were analyzed by using the Brookfield software Rheocalc version (2.6). IPC Paste and Power Law (PL) math models 
provide a numerically and graphically analyze the behavior of data sets.

3.1. Power Law. The Power Law equation is $\tau=k D^{n}$ where

$$
\begin{aligned}
& \tau=\text { shear stress, } \\
& D=\text { yield stress (stress at zero shear rate), } \\
& k=\text { plastic viscosity, } \\
& n=\text { shear rate. }
\end{aligned}
$$

The calculated parameters for this model are

$$
\begin{aligned}
& \text { flow index (no units), } \\
& \text { consistency index (cP), } \\
& \text { confidence of fit (\%). }
\end{aligned}
$$

3.2. IPC Paste Analysis. This method is intended to calculate the shear sensitivity factor and the 10 RPM viscosity value of creams. The paste equation is, $\eta=k R^{n}$ where

$$
\begin{aligned}
& \eta=\text { viscosity }(\mathrm{cP}), \\
& k=\text { consistency multiplier, } \\
& R=\text { rotational speed (RPM), } \\
& n=\text { shear sensitivity factor, }
\end{aligned}
$$

The calculated parameters for this model are

shear sensitivity factor (no units),

10 RPM viscosity (cP),

confidence of fit (\%).

\section{Results and Discussion}

The change in absorbency produced by reduced DPPH was used to evaluate the antioxidant ability of the plant extract and cream containing AN extract. The antioxidant activity of plant extract and after addition of plant extract of the cream was found to be $89 \%$ and $83 \%$, respectively. The antioxidant potential of the extract studied here could be attributed to flavonoids, tannins, proteins, and reducing sugars. The key role of phenolic compounds as scavengers of free radicals is emphasized in several reports [15]. Phenolic compounds are known to have antioxidant activity, and it is likely that the activity of the extract may be due to these compounds. This activity is believed to be mainly due to their redox properties, which play an important role in adsorbing and neutralizing free radicals, quenching singlet and triplet oxygen, or decomposing peroxides [10]. The cream containing extract showed lower H-donor capability. These results may be due to the presence of the formulation components in the reaction mixture. Since the DPPH scavenging is measured by spectroscopy, the formulation components may interfere with the antioxidant measurement [16]. In this study, the $\mathrm{pH}$, base and active cream was 5.25 and 5.1, respectively, which is within the range of skin $\mathrm{pH}$ [17]. By applying ANOVA, it was found that the change in $\mathrm{pH}$ of different samples of base and active cream was not significant at different time intervals and temperature.

The colors of freshly prepared base and active cream were white and light orange, respectively. There was no change in color of any sample of base and active cream at different storage conditions during study period. No change in color may be attributed to different factors that relate to cream stability including the components of oil phase, paraffin oil, and Abil EM 90 which are colorless, transparent, and nontoxic liquids. Silicone surfactants show characteristic properties which make their use very attractive to the cosmetic industry. They get better the visual property by eliminating high-melting-point waxes. The persistence of the surfactant is exclusively dominated by its surface activity to prevent coalescence of the dispersed water phase. Surfactant molecules adsorb on the surface of the dispersed phase and lower interfacial tension between oil and aqueous phases. Finally, they provide emulsion stability against flocculation and coalescence of the dispersed phase [18]. Conductivity is a measure of amount of free water and free ions. High or low conductivity values reveal that there is less or more lamellar water and more free water in the creams, which can be seen as a decrease or increase in the consistency of creams, respectively [12]. No electrical conductivity was found in any sample of base and active cream throughout the study period. This is because the cream is of w/o type and oil being the continuous phase contributes to no passage of current [19]. Centrifugation tests for base and active cream kept at different storage conditions were performed using centrifuge machine for a period of two months at different time intervals. No phase separation after centrifugation was found in any of the samples of base and active cream kept at $8^{\circ} \mathrm{C}, 25^{\circ} \mathrm{C}$, and $40^{\circ} \mathrm{C}+75 \% \mathrm{RH}$. However, slight phase separation was observed for the samples of both active cream and base kept at $40^{\circ} \mathrm{C}$ after 42 days time period. There was no liquefaction in any of the samples kept at $8^{\circ} \mathrm{C}$ and $25^{\circ} \mathrm{C}$. The samples were stable at $8^{\circ} \mathrm{C}$ and $25^{\circ} \mathrm{C}$, but slight phase separation in the sample of base occurred at $40^{\circ} \mathrm{C}$ and $40^{\circ} \mathrm{C}+$ $75 \% \mathrm{RH}$ on the 50th day of observation whereas the active cream was stable. This may be due to the antimicrobial properties of Acacia nilotica which protects the cream from microbial contamination and degradation [8].

4.1. Physical Stability Evaluation. Rheological parameters of both base and active cream kept at different conditions up to two months were noted and have been given in Tables 2, 3, and 4. Rheograms of the active creams have been demonstrated in Figures 1, 2, 3, 4, and 5. Viscosities of both base and active cream are presented in Tables 5 and 6. Persistent and interminable interest in the comprehension of nature and peculiarities of the rheological properties of emulsions is determined by the challenge given by numerous and unexpected effects observed in the flow of emulsions. This interest is also strongly and undyingly aggravated by the tribulations of pharmaceuticals, cosmetic, and food industries, which produces and consumes many hundred thousand tons of emulsions of various contents, properties, and functions. It is the plenty of chemical compounds and the variation of their nature in composing these 
TABLE 2: Rheological parameters of freshly prepared base and active cream.

\begin{tabular}{lccc}
\hline Model & Rheological parameter & Base & Active cream \\
\hline \multirow{3}{*}{ Power Law } & Consistency index (cP) & 332.9 & 212.1 \\
& Flow index & 0.56 & 0.61 \\
\hline \multirow{3}{*}{ IPC Paste } & Confidence of fit (\%) & 99.8 & 99.3 \\
& 10 RPM viscosity (cP) & 88.1 & 66.1 \\
& Shear sensitivity & 0.44 & 0.39 \\
\hline
\end{tabular}

TABLE 3: Rheological parameters at four weeks of base and active cream kept at $25^{\circ} \mathrm{C}, 40^{\circ} \mathrm{C}, 40^{\circ} \mathrm{C}+\mathrm{RH} 75 \%$, and $8^{\circ} \mathrm{C}$.

\begin{tabular}{|c|c|c|c|c|c|c|c|c|c|}
\hline \multirow{2}{*}{ Model } & \multirow{2}{*}{ Rheological parameter } & \multicolumn{2}{|r|}{ At $25^{\circ} \mathrm{C}$} & \multicolumn{2}{|r|}{ At $40^{\circ} \mathrm{C}$} & \multicolumn{2}{|c|}{ At $40^{\circ} \mathrm{C}+\mathrm{RH} 75 \%$} & \multicolumn{2}{|r|}{ At $8^{\circ} \mathrm{C}$} \\
\hline & & Base & Active cream & Base & Active cream & Base & Active cream & Base & Active cream \\
\hline \multirow{3}{*}{ Power Law } & Consistency index (cP) & 909.5 & 4741 & 9.38 & 1365 & 254.8 & 1798 & 1664 & 2036 \\
\hline & Flow index & 0.33 & 0.24 & 13.1 & 0.43 & 0.54 & 0.39 & 0.20 & 0.35 \\
\hline & Confidence of fit (\%) & 95.4 & 98.7 & 99.1 & 99.6 & 99.1 & 99.5 & 92.4 & 99.6 \\
\hline \multirow{3}{*}{ IPC Paste } & 10 RPM viscosity $(\mathrm{cP})$ & 120.9 & 485.1 & 6.19 & 244.6 & 65.1 & 288.4 & 150.4 & 294.6 \\
\hline & Shear sensitivity & 0.67 & 0.76 & 4.5 & 0.57 & 0.46 & 0.61 & 0.80 & 0.65 \\
\hline & Confidence of fit (\%) & 95.4 & 98.7 & 98.9 & 99.6 & 99.1 & 99.5 & 92.4 & 99.6 \\
\hline
\end{tabular}

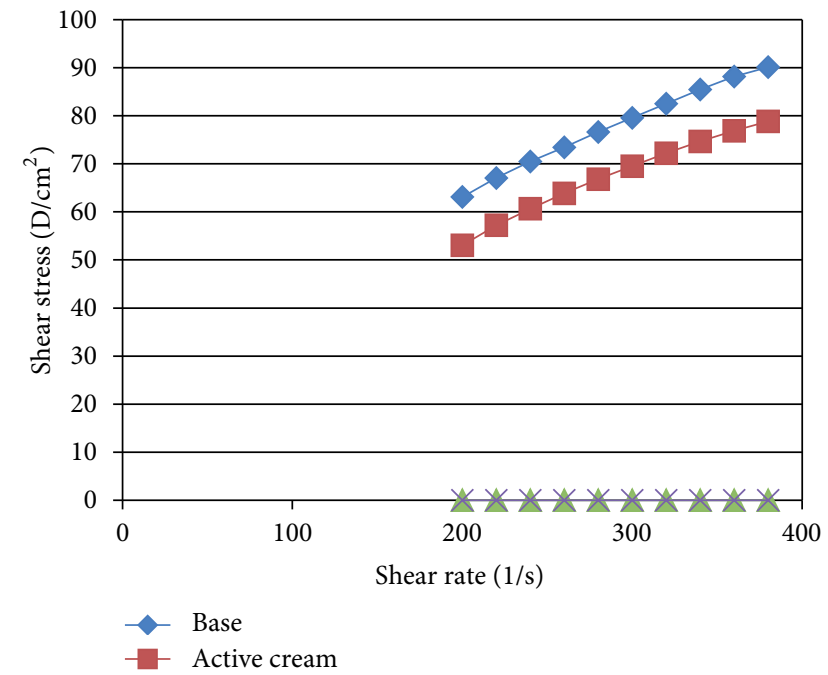

FIGURE 1: Rheograms of freshly prepared base and active cream. Analyses were performed at $25^{\circ} \mathrm{C}$.

multi-component materials that are the fundamental reasons for unexpected and new effects in the behavior of emulsions [20]. Rheological analyses are necessary to define and optimize stability and permit assessment of creams that undergo changes induced by aging, shear and temperature, and stability. Moreover, the rheological properties allow describing and controlling the disruption mechanisms of the oily globules, which occur either by an osmotic swelling or simple shear flow [21]. Changes in the rheological properties of creams symbolize important early warnings of forthcoming failure of the product [22]. In this study, a computerized cone-plate rheometer was used. All the rheological tests were performed at $25^{\circ} \mathrm{C}$. Increasing shear stresses were applied to the samples,

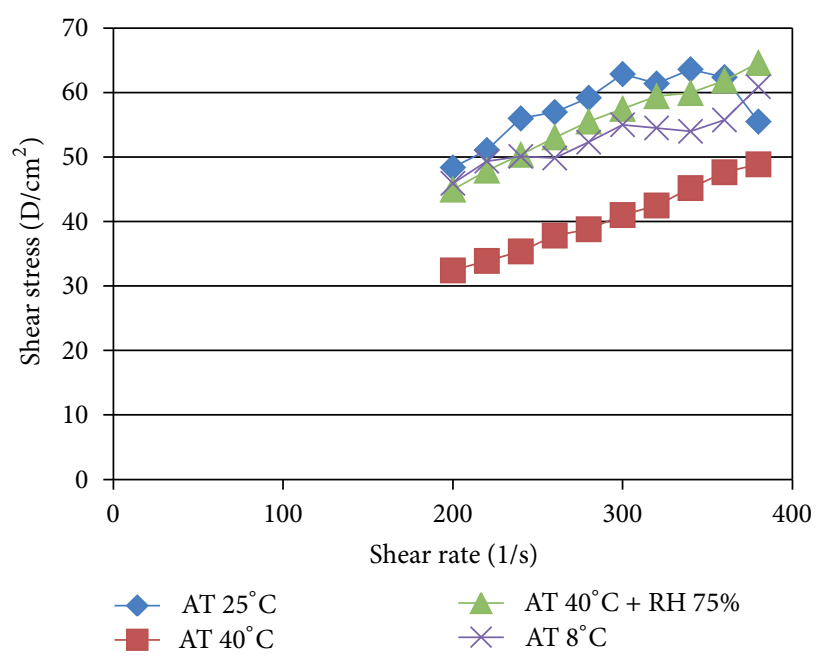

FIGURE 2: Rheograms of base at four weeks kept at $25^{\circ} \mathrm{C}, 40^{\circ} \mathrm{C}, 40^{\circ} \mathrm{C}$ $+\mathrm{RH} 75 \%$, and $8^{\circ} \mathrm{C}$.

and the changes in viscosities were noted. These rheological tests were performed on freshly prepared base and on samples (active cream) stored at different conditions at $8^{\circ} \mathrm{C}, 25^{\circ} \mathrm{C}$, and $40^{\circ} \mathrm{C}$ and at $40^{\circ} \mathrm{C}$ with $70 \% \mathrm{RH}$ (relative humidity) for a period of two months. Rheograms of shear stress versus shear rate were obtained. Then mathematical models, that is, Power Law and IPC Paste analyses, were applied to the rheograms. Power Law was found to fit to all the rheograms, and the confidences of fit were found to be in the range of 94.9-99.2\%. IPC paste provides the data of confidence of fit 98.7-99.9\%. 
TABLE 4: Rheological parameters at eight weeks of base and active cream kept at $25^{\circ} \mathrm{C}, 40^{\circ} \mathrm{C}, 40^{\circ} \mathrm{C}+\mathrm{RH} 75 \%$, and $8^{\circ} \mathrm{C}$.

\begin{tabular}{lccccccccc}
\hline \multirow{2}{*}{ Model } & \multirow{2}{*}{ Rheological parameter } & \multicolumn{2}{c}{ At $25^{\circ} \mathrm{C}$} & \multicolumn{2}{c}{ At $40^{\circ} \mathrm{C}$} & \multicolumn{2}{c}{ At $40^{\circ} \mathrm{C}+\mathrm{RH} 75 \%$} & \multicolumn{2}{c}{ At $8^{\circ} \mathrm{C}$} \\
& & Base & Active cream & Base & Active cream & Base & Active cream & Base & Active cream \\
\hline \multirow{3}{*}{ Power Law } & Consistency index (cP) & 296.7 & 2069 & 205.3 & 624.2 & 420.7 & 922.7 & 229.8 & 2247 \\
& Flow index & 0.46 & 0.39 & 0.50 & 0.50 & 0.46 & 0.47 & 0.56 & 0.29 \\
& Confidence of fit (\%) & 98.8 & 99.8 & 89.6 & 99.9 & 97.9 & 99.8 & 99.4 & 99.2 \\
\hline \multirow{3}{*}{ IPC Paste } & 10 RPM viscosity (cP) & 58.4 & 330.4 & 45.2 & 137.9 & 83.2 & 188.1 & 61.9 & 267.9 \\
& Shear sensitivity & 0.54 & 0.61 & 0.50 & 0.50 & 0.54 & 0.53 & 0.44 & 0.71 \\
& Confidence of fit (\%) & 98.8 & 99.8 & 89.6 & 99.9 & 97.9 & 99.8 & 99.4 & 99.2 \\
\hline
\end{tabular}

TABLE 5: Viscosities (cP) of base at different temperatures and time intervals.

\begin{tabular}{|c|c|c|c|c|c|c|c|c|}
\hline \multirow{2}{*}{ Fresh } & \multicolumn{2}{|c|}{ At $25^{\circ} \mathrm{C}$} & \multicolumn{2}{|c|}{ At $40^{\circ} \mathrm{C}$} & \multicolumn{2}{|c|}{ At $40^{\circ} \mathrm{C}+75 \% \mathrm{RH}$} & \multicolumn{2}{|c|}{ At $8^{\circ} \mathrm{C}$} \\
\hline & 4 weeks & 8 weeks & 4 weeks & 8 weeks & 4 weeks & 8 weeks & 4 weeks & 8 weeks \\
\hline 3875.568 & 2970.728 & 2020.699 & 1990.539 & 1794.501 & 2759.611 & 2910.409 & 2819.93 & 2744.531 \\
\hline 3742.944 & 2851.461 & 1946.67 & 1891.834 & 1727.327 & 2673.244 & 2796.625 & 2755.498 & 2659.535 \\
\hline 3606.636 & 2865.17 & 1859.847 & 1809.581 & 1558.25 & 2576.139 & 2689.238 & 2563.573 & 2576.139 \\
\hline 3467.872 & 2691.171 & 1821.181 & 1786.381 & 1577.583 & 2505.573 & 2656.372 & 2354.775 & 2482.374 \\
\hline 3361.036 & 2595.887 & 1755.724 & 1701.868 & 1497.213 & 2434.317 & 2477.402 & 2294.29 & 2412.774 \\
\hline 3256.656 & 2573.626 & 1678.889 & 1678.889 & 1417.505 & 2352.455 & 2332.349 & 2251.923 & 2332.349 \\
\hline 3167.012 & 2356.225 & 1573.958 & 1630.508 & 1112.138 & 2280.826 & 2101.753 & 2092.328 & 2271.401 \\
\hline 3087.192 & 2297.458 & 1507.984 & 1632.171 & 1002.366 & 2164.401 & 2208.753 & 1374.927 & 2208.753 \\
\hline 3007.372 & 2127.933 & 1491.229 & 1625.272 & 1533.117 & 2111.178 & 2169.821 & 1901.735 & 2136.311 \\
\hline 2912.816 & 1793.707 & 1452.427 & 1579.415 & 1531.794 & 2087.367 & 2142.925 & 1968.316 & 2071.494 \\
\hline
\end{tabular}

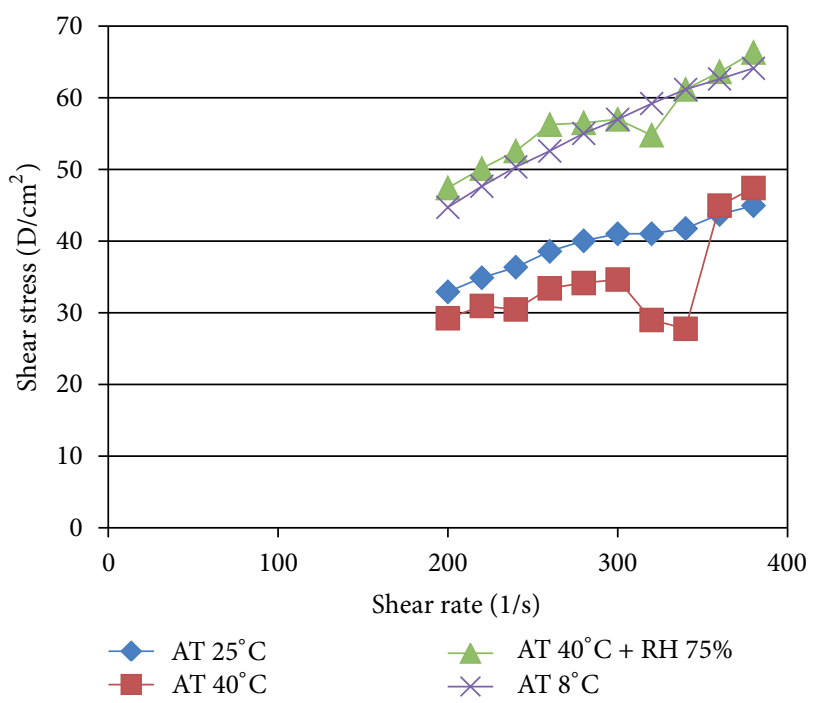

FIGURE 3: Rheograms of base at eight weeks kept at $25^{\circ} \mathrm{C}, 40^{\circ} \mathrm{C}, 40^{\circ} \mathrm{C}$ $+\mathrm{RH} 75 \%$, and $8^{\circ} \mathrm{C}$.

Viscosities were found to decrease in parallel to the increase in shear stress. Power Law and IPC analysis were found to fit all the rheograms. It was found that viscosities of the freshly prepared base were decreased with increase in the stresses from $3875.568 \mathrm{cP}$ to $2912.816 \mathrm{cP}$, and also the samples of base at $25^{\circ} \mathrm{C}, 40^{\circ} \mathrm{C}, 40^{\circ} \mathrm{C}+\mathrm{RH} 75 \%$, and $8^{\circ} \mathrm{C}$ after four weeks and eight weeks were found to have the same behavior as shown in Table 5. Viscosity of freshly prepared active cream containing AN extract was found to be $3256.656 \mathrm{cP}$ which was decreased to $2548.1 \mathrm{cP}$ by increasing shear stress and also the sample of active cream at $25^{\circ} \mathrm{C}$, $40^{\circ} \mathrm{C}, 40^{\circ} \mathrm{C}+\mathrm{RH} 75 \%$, and $8^{\circ} \mathrm{C}$ after one month and two months. The rheograms of all formulations indicated nonNewtonian behavior, with flow index less than 1 which was a pleasing rheological property in these preparations reflecting their pseudoplastic tendency. Formulations with a pseudoplastic flow cause the production of a coherent film covering the skin surface. This characteristic is beneficial and crucial for a better phenolic antioxidant protection of the skin surface. The reason of pseudoplastic flow may be due to the progressive disintegration of the internal structure of the creams, under increasing shear, and its later reconstruction by means of Brownian movement [23]. However, the silicone emulsifier (silicone polymer) supports a product more stable and reliable. This generates an emulsion with a very strong interfacial film due to steric crowding [11].

Although flow indexes were altered by stress and consistency, indexes of active cream increased significantly but no increase in base (Tables 2, 3, and 4). Most researchers have reported that consistency indexes normally decline during storage mentioning instability of product [24], but in our results the consistency index was increased in active cream significantly. It is possible that this was due to the interaction 
TABLE 6: Viscosities (cP) of active cream at different temperatures and time intervals.

\begin{tabular}{lcccccccc}
\hline \multirow{2}{*}{ Fresh } & \multicolumn{2}{c}{ At $25^{\circ} \mathrm{C}$} & \multicolumn{2}{c}{ At $40^{\circ} \mathrm{C}$} & \multicolumn{2}{c}{ At $40^{\circ} \mathrm{C}+75 \% \mathrm{RH}$} & \multicolumn{2}{c}{ At $8^{\circ} \mathrm{C}$} \\
& 4 weeks & 8 weeks & 4 weeks & 8 weeks & 4 weeks & 8 weeks & 4 weeks & 8 weeks \\
\hline 3256.656 & 10148.73 & 9862.215 & 7962.156 & 5293.024 & 8595.509 & 6816.088 & 8128.034 \\
3194.028 & 9541.426 & 9335.792 & 7581.047 & 5058.601 & 8156.823 & 6443.204 & 7690.718 \\
3104.384 & 8997.638 & 8859.406 & 7225.757 & 4838.115 & 7778.684 & 6170.168 & 7288.589 & 5653.533 \\
3015.968 & 8514.31 & 8456.31 & 6913.527 & 4651.551 & 7423.921 & 5915.937 & 6925.127 & 5370.743 \\
2930.008 & 8100.028 & 8089.257 & 6635.13 & 4480.867 & 7109.067 & 5698.025 & 6624.358 & 5105.603 \\
2845.276 & 7710.825 & 7740.985 & 6383.799 & 4332.941 & 6816.088 & 5489.062 & 6343.586 & 4865.762 \\
2770.368 & 7351.422 & 7436.246 & 6145.035 & 4184.656 & 6531.456 & 5315.644 & 6079.061 & 4637.051 \\
2696.688 & 6963.338 & 7149.618 & 5916.62 & 4062.686 & 6280.31 & 5136.016 & 5819.044 & 4399.765 \\
2621.78 & 6593.241 & 6869.705 & 5705.206 & 3937.514 & 6057.069 & 4976.347 & 5587.918 & 4205.6 \\
2548.1 & 6095.43 & 6754 & 5500.173 & 3833.454 & 5777.96 & 4825.549 & 5357.312 & 4000.126 \\
\hline
\end{tabular}

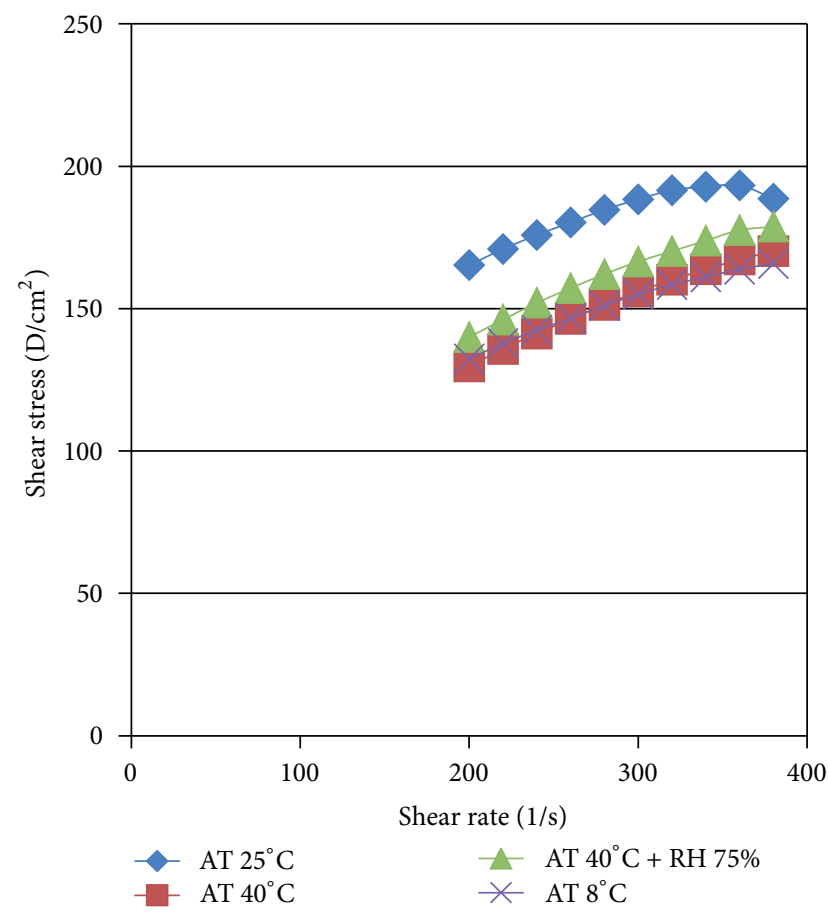

Figure 4: Rheograms of active cream at four weeks kept at $25^{\circ} \mathrm{C}$, $40^{\circ} \mathrm{C}, 40^{\circ} \mathrm{C}+\mathrm{RH} 75 \%$ and $8^{\circ} \mathrm{C}$.

of AN extract containing phenolic compounds and the vehicle polymer. It is demonstrated by an artifact when the decomposition products were analyzed by mass spectrometry [24]. Various factors may be influenced on the stability of system, and it is reported that that electrolytes dissolved in the aqueous phase of concentrated W/O emulsion dramatically increased emulsion stability. The electrolytes appear to develop the stability of these water-in-oil emulsions by increasing the resistance of the water droplets to coalescence [11].

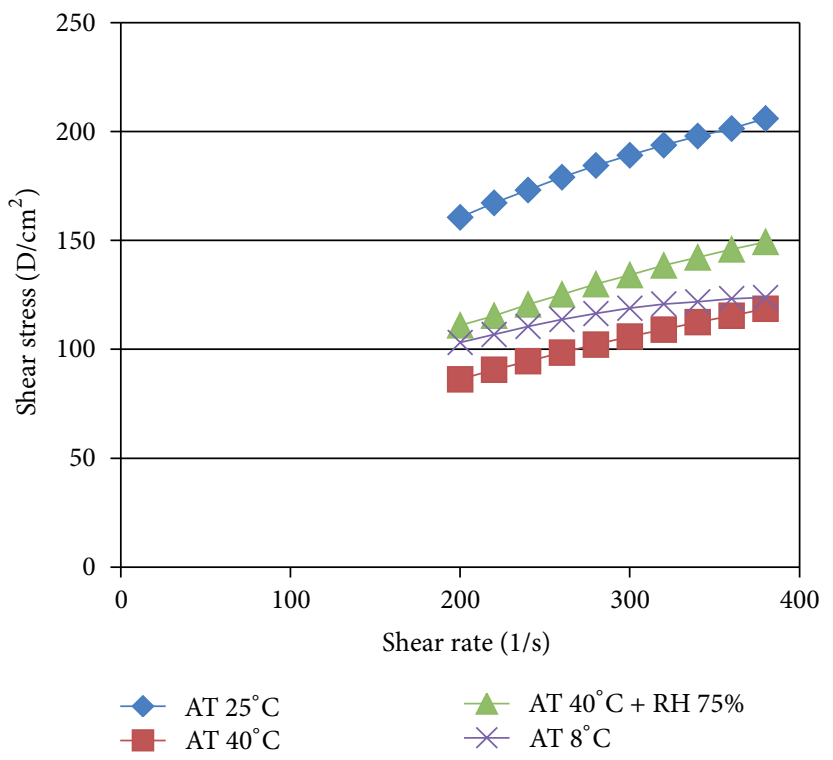

FIGURE 5: Rheograms of active cream at eight weeks kept at $25^{\circ} \mathrm{C}$, $40^{\circ} \mathrm{C}, 40^{\circ} \mathrm{C}+\mathrm{RH} 75 \%$ and $8^{\circ} \mathrm{C}$.

Thus, the safety and efficacy the system proposed in this study is acceptable only if the product is to be used in a restricted period of time.

\section{Conclusions}

Acacia nilotica is an interesting source of plant phenolic antioxidants which can be used topically for protection and other skin functions. Rheology measurements provide a simple and effective means to compare the structural properties of creams. The most elastic structure is supposed to be able to maintain structural stability and resistance to external forces for specific period of time. Further studies have to be done to authenticate that these properties still 
subsist when the active cream is applied on skin as well as with other activities.

\section{Acknowledgments}

The authors wish to thank the Higher Education Commission of Pakistan for providing financial support to conduct the study. The authors also acknowledge the moral support given by the Chairman and Dean of the Faculty of Pharmacy and Alternative Medicine, The Islamia University of Bahawalpur, Pakistan. In addition, the authors do not have any conflict of interest.

\section{References}

[1] G. G. Duthie, P. T. Gardner, and J. A. M. Kyle, "Plant polyphenols: are they the new magic bullet?" Proceedings of the Nutrition Society, vol. 62, no. 3, pp. 599-603, 2003.

[2] T. Aburjai and F. M. Natsheh, "Plants used in cosmetics," Phytotherapy Research, vol. 17, no. 9, pp. 987-1000, 2003.

[3] D. M. Pereira, P. Valentão, J. A. Pereira, and P. B. Andrade, "Phenolics: from chemistry to biology," Molecules, vol. 14, no. 6, pp. 2202-2211, 2009.

[4] V. Muguet, M. Seiller, G. Barratt, O. Ozer, J. P. Marty, and J. L. Grossiord, "Formulation of shear rate sensitive multiple emulsions," Journal of Controlled Release, vol. 70, no. 1-2, pp. 37-49, 2001.

[5] J. R. Avendano-Gomez, J. L. Grossiord, and D. Clausse, "Study of mass transfer in oil-water-oil multiple emulsions by differential scanning calorimetry," Journal of Colloid and Interface Science, vol. 290, no. 2, pp. 533-545, 2005.

[6] R. Sundaram and S. K. Mitra, "Antioxidant activity of ethyl acetate soluble fraction of Acacia arabica bark in rats," Indian Journal of Pharmacology, vol. 39, no. 1, pp. 33-38, 2007.

[7] B. Sultana, F. Anwar, and M. Ashraf, "Effect of extraction solvent/technique on the antioxidant activity of selected medicinal plant extracts," Molecules, vol. 14, no. 6, pp. 2167-2180, 2009.

[8] A. Banso, "Phytochemical and antibacterial investigation of bark extracts of Acacia nilotica," Journal of Medicinal Plant Research, vol. 3, no. 2, pp. 082-085, 2009.

[9] T. Kalaivani, C. Rajasekaran, and L. Mathew, "Free radical scavenging, cytotoxic, and hemolytic activities of an active antioxidant compound ethyl gallate from leaves of Acacia nilotica(L.) wild. Ex. selile subsp. indica (Benth.) Brenan," Journal of Food Science, vol. 76, no. 6, pp. T144-T149, 2011.

[10] A. Svobodová, J. Psotová, and D. Walterová, "Natural phenolics in the prevention of UV-induced skin damage. A review," Biomedical papers of the Medical Faculty of the University Palacký, vol. 147, no. 2, pp. 137-145, 2003.

[11] P. Clément, C. Laugel, and J. P. Marty, "In vitro release of caffeine from concentrated W/O emulsions: effect of formulation parameters," International Journal of Pharmaceutics, vol. 207, no. 1-2, pp. 7-20, 2000.

[12] M. Korhonen, H. Niskanen, J. Kiesvaara, and J. Yliruusi, "Determination of optimal combination of surfactants in creams using rheology measurements," International Journal of Pharmaceutics, vol. 197, no. 1-2, pp. 143-151, 2000.

[13] K. Hamid, M. Rani, S. Kaniz, F. Urmi, R. Habib, and M. M. Rahman, "Screening of different parts of the plant pandanus odorus for its antioxidant," International Journal of Applied
Biology and Pharmaceutical Technology, vol. 1, no. 3, pp. 1364-1368, 2010

[14] D. O. Kim, K. W. Lee, H. J. Lee, and C. Y. Lee, "Vitamin C equivalent antioxidant capacity (VCEAC) of phenolic phytochemicals," Journal of Agricultural and Food Chemistry, vol. 50, no. 13, pp. 3713-3717, 2002.

[15] A. Wojdyło, J. Oszmiański, and R. Czemerys, "Antioxidant activity and phenolic compounds in 32 selected herbs," Food Chemistry, vol. 105, no. 3, pp. 940-949, 2007.

[16] S.-W. Huang, E. N. Frankel, and J. B. German, "Antioxidant activity of $\alpha$ - and $\gamma$-tocopherols in bulk oils and in oil-in-water emulsions," Journal of Agricultural and Food Chemistry, vol. 42, no. 10, pp. 2108-2114, 1994.

[17] J. L. Matousek, K. L. Campbell, I. Kakoma, P. F. Solter, and D. J. Schaeffer, "Evaluation of the effect of $\mathrm{pH}$ on in vitro growth of Malassezia pachydermatis," Canadian Journal of Veterinary Research, vol. 67, no. 1, pp. 56-59, 2003.

[18] M. H. Choi, S. Jeong, S. I. Nam, S. E. Shim, and Y. H. Chang, "Rheology of decamethylceclopentasiloxane (cyclomethicone) W/O emulsion system," Macromolecular Research, vol. 17, no. 12, pp. 943-949, 2009.

[19] J. Kizling, B. Kronberg, and J. C. Eriksson, "On the formation and stability of high internal phase O/W emulsions," Advances in Colloid and Interface Science, vol. 123-126, pp. 295-302, 2006.

[20] S. R. Derkach, "Rheology of emulsions," Advances in Colloid and Interface Science, vol. 151, no. 1-2, pp. 1-23, 2009.

[21] T. Tadros, "Application of rheology for assessment and prediction of the long-term physical stability of emulsions," Advances in Colloid and Interface Science, vol. 108-109, pp. 227-258, 2004.

[22] M. Korhonen, L. Hellen, J. Hirvonen, and J. Yliruusi, "Rheological properties of creams with four different surfactant combinations-effect of storage time and conditions," International Journal of Pharmaceutics, vol. 221, no. 1-2, pp. 187-196, 2001.

[23] L. R. Gaspar and P. M. B. G. Maia Campos, "Rheological behavior and the SPF of sunscreens," International Journal of Pharmaceutics, vol. 250, no. 1, pp. 35-44, 2003.

[24] T. Guaratini, M. D. Gianeti, and P. M. B. G. M. Campos, "Stability of cosmetic formulations containing esters of Vitamins $\mathrm{E}$ and A: chemical and physical aspects," International Journal of Pharmaceutics, vol. 327, no. 1-2, pp. 12-16, 2006. 

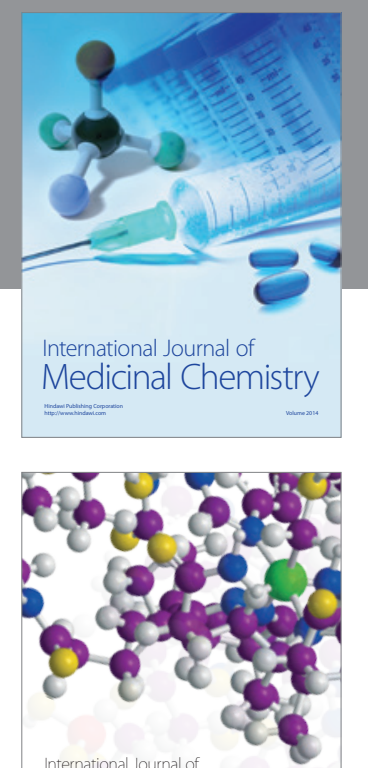

\section{Carbohydrate} Chemistry

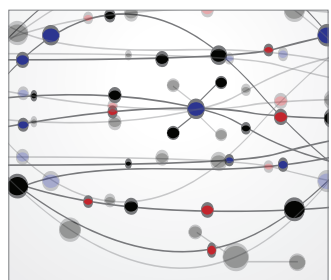

The Scientific World Journal
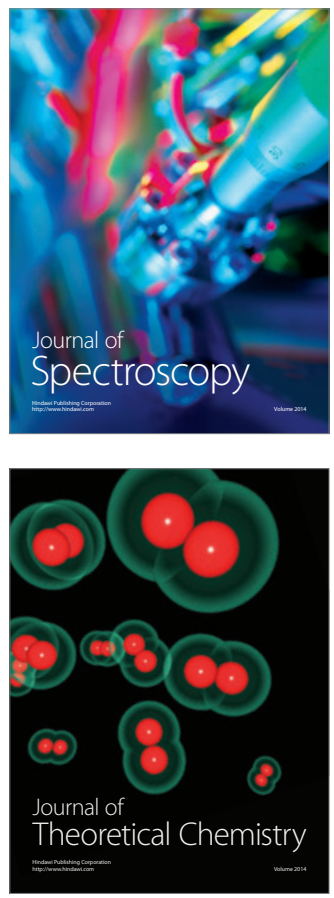
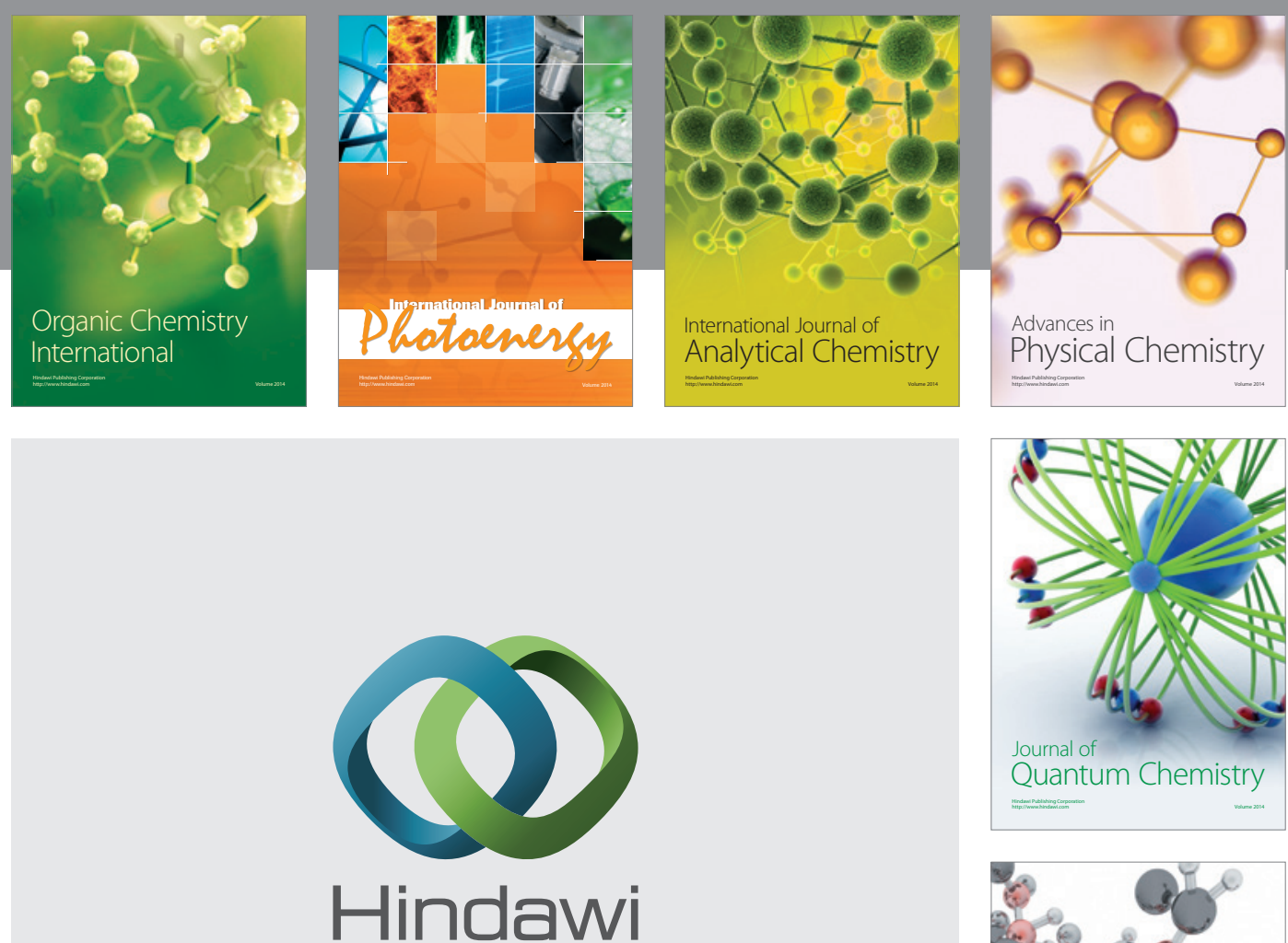

Submit your manuscripts at

http://www.hindawi.com

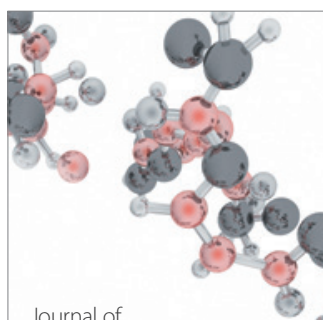

Analytical Methods

in Chemistry

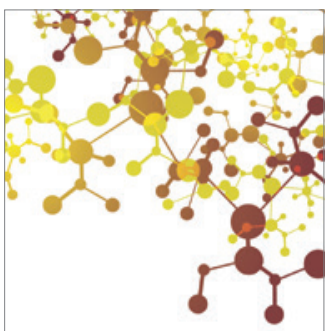

Journal of

Applied Chemistry

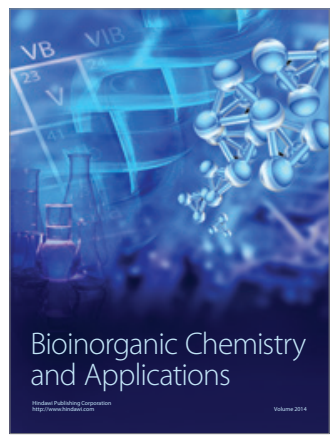

Inorganic Chemistry
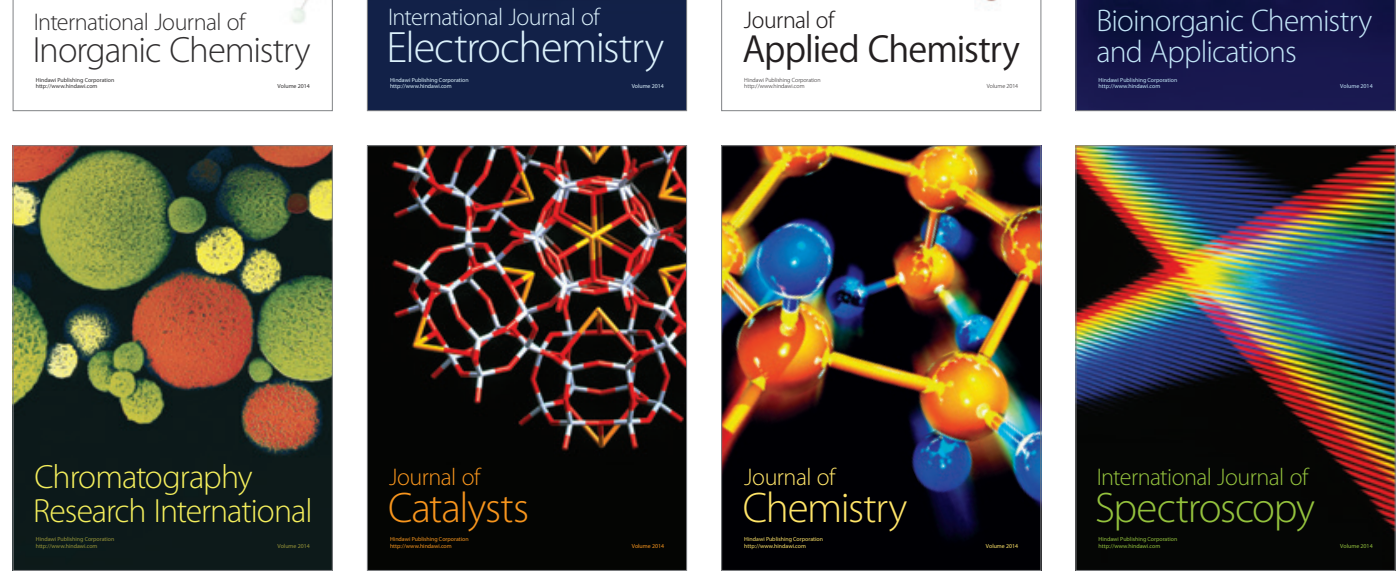